\title{
Evaluation of chitosan/sisal fiber/polyethylene membranes
}

\author{
O. Agboola ${ }^{\text {a,b,c,* }}$, O.S.I. Fayomi ${ }^{\text {b,e }}$, E.R. Sadiku ${ }^{\mathrm{b}}$, A. Ayoola ${ }^{\mathrm{a}}$, T. Mokrani $^{\mathrm{c}}$, B.S. Mbuli $^{\mathrm{d}}$, P. Popoola ${ }^{\mathrm{b}}$, \\ G. Perry ${ }^{\mathrm{f}}$
}

a Department of Chemical Engineering, Covenant University, Ota, Nigeria

${ }^{\mathrm{b}}$ Department of Chemical, Metallurgical and Materials Engineering, Tshwane University of Technology, Pretoria, South Africa

${ }^{\mathrm{c}}$ Department of Civil and Chemical Engineering, University of South Africa, Johannesburg, South Africa

d Department of Applied Chemistry, University of Johannesburg, South Africa

e Department of Mechanical Engineering, Covenant University, Ota, Nigeria

${ }^{\mathrm{f}}$ Material Science and Manufacturing, Council of Scientific and Industrial Research, South Africa

\section{A R T I C L E I N F O}

\section{Article history:}

Received 7 April 2020

Received in revised form 25 June 2020

Accepted 28 June 2020

Available online $\mathrm{xxxx}$

\section{Keywords:}

Porosity

Water permeability

SEM

XRD

FTIR

Flux

\begin{abstract}
A B S T R A C T
Composites of ternary blend of chitosan/sisal fiber/high density polyethylene, were prepared by using the Rheomixer, followed by hot press, in order to form dense microfiltration membranes. The effective operation of the membranes was tested via the utilization of distilled water. The structural arrangement of the membranes was examined with the aid of using scanning electron microscopy (SEM). The chemical structure and phase identification of the membranes were examined using attenuation total reflectioninfrared spectroscopy (ATR-IR) and X-ray diffraction (XRD), respectively. The water permeability of the composite membranes is dependent on how rough the surface is, the sizes of pores and the membrane porosity. The membranes with highest amount of sisal fiber, gave highest flux of $1.4 \mathrm{~m}^{3} / \mathrm{m}^{2} / \mathrm{h}$.

(C) 2020 Elsevier Ltd. All rights reserved.

Selection and peer-review under responsibility of the scientific committee of the International Conference on Advanced Materials Behavior and Characterization.
\end{abstract}

\section{Introduction}

Diverse kinds of thermoplastic exist; however, Polyethylene (PE) is extensively used for the reason of having good properties, such as: having moisture absorption that is virtually zero, it is not difficult to process, it has outstanding chemical inertness, the coefficient of friction is low, it possess excellent toughness and low electrical conductivity [1]. There is great interest in the utilization of PE material for the fabrication of porous membranes; attributing its affordability, excellent mechanical properties, and chemical stability. In the pedigree of polyolefin, one of the polyolefin that is frequently used is high density polyethylene (HDPE); the frequent use is ascribe to its accessibility, affordability competitive and obvious mechanical characteristics. Though the rate at which it is been utilized is high, it has a poor thermal stability; in addition, it is an insulating polymer [2]; however, the main significant distinct physical property of a polymer is its molecular weight [3]. The method of enhancing the thermal stability, which is dependent on the utilization of polymer composite has recently

\footnotetext{
* Corresponding author.

E-mail addresses: agboolaoranti@gmail.com (O. Agboola), ojo.fayomi@covenantuniversity.edu.ng (O.S.I. Fayomi).
}

advanced [4]. The advancement of membranes that involves the integration of engineered polymer blends in membrane matrix, is exceedingly recognized in membrane technology [5].

Natural fiber and reinforced polymer composites have attracted great interest among engineers and material scientists. Reinforcements that improve the mechanical properties of the polymer composite, are usually stronger than the polymer matrix [6]. There is need to understand the structural and mechanical behaviour of the fibers in order to utilize them for high performance composites [7]. Among the polysaccharides, Chitosan (C) is one of the most abundant in nature. It possesses excellent biological, physical, and eco-friendly properties [8]. Chitosan is of high molecular weight co-polymer that has radicals chain composed of acetylglucosamine and glucosamine. There is room for an easy chemical modification due to the active groups in chitosan molecules [9]. There are lots of ongoing recent research on Mixed-matrix membranes (MMMs) because they possess advanced properties such as antifouling behaviour [10-12]. This study reports the evaluation of ternary blends composite membranes in relation to their structural properties and permeability. The effects of sisal fiber and chitosan on the composite microfiltration membranes are investigated by examining the pores and morphological structure. 


\section{Materials and methods}

Chitosan of high purity and of medium molecular weight was purchased from Sigma Aldrich, South Africa. HDPE was obtained from KR Polymer, Kryasan; Johannesburg, South Africa. It is a pre-consumer waste. The sisal fiber was obtained from Port Elizabeth, South Africa.

\subsection{Preparation of sisal fibers}

Liquid nitrogen was poured into a thermal cooling box and was utilized for soaking the strands of decorticated sisal fibre for 1 day at ambient temperature for the purpose of making the material brittle. The sisal fibre from the liquid nitrogen has the same appearance as before it was soaked in the liquid nitrogen. The brittle sisal fibre was crushed with the aid of a hammer milling machine for the purpose of pulverization and reduction of material size. The fiber was further milled to powder of $0.02 \mathrm{~cm}$, with the aid of pin milling machine. The sisal powder was dried with the aid of air circulating oven at $65^{\circ} \mathrm{C}$ because of its hydrophilic nature. Liquid nitrogen was used because the temperature $(65 \mathrm{~K})$ at which it freezes makes it to have a higher thermal capacity with low viscosity and it is non-toxic. Furthermore, Liquid nitrogen has high efficiency with low cost.

\subsection{Preparation of blends}

A counter-rotating mixer (Haake Rheomix OS) was used to melt blend $50 \mathrm{~g}$ composite at $190^{\circ} \mathrm{C}$ for $10 \mathrm{~min}$ with a constant rotor speed of $60 \mathrm{rpm}$ for the purpose of promoting an even mixing distribution. Table 1 shows the composition of the membrane composites used in this study. The moulds of the blends were taken to the milling department of the CSIR, Pretoria to crush to powder of $0.03 \mathrm{~cm}$. Blended samples were fabricated via melt pressing in a hydraulic press at $120^{\circ} \mathrm{C}$ and then melt-compressed for five minutes at 35 bar, which was cooled at ambient temperature fifteen minutes at 20 bar. The composite average thickness was $0.55 \mathrm{~mm}$. The basis of the blending ratio was based on the compatibility of the polymers with sisal fiber.

\subsection{Characterization of materials}

Scanning electron microscopy (SEM), Joel Field Emission Electron Microscope JESM-7600F was utilized to envision the surfaces of the composites. The magnification of the SEM images was $\times 5000$. Fourier-transform infrared spectroscopy (FT-IR), Perkin Elmer 16PC FTIR instrument was the tool used for the interpretation of the existence and type of interactions that exist between the molecules of HDPE, chitosan and sisal fiber. The FTIR spectra of the membranes were recorded in the region of $4000-500$ " $\mathrm{cm}^{-1}$ ". $\mathrm{X}$-ray diffraction (XRD) was utilized for the identification of chemical phase in the composites. WAXD Pan Analytical Xpert Pro diffractometer, employing a CuKa radiation having a voltage of $45 \mathrm{kV}$, wavelength of $0.15 \mathrm{~nm}$, and a current $40 \mathrm{~mA}$ was utilized for the XRD characterization of the composites.

\subsection{Filtration experiment}

The filtration study was done in a $250 \mathrm{~mL}$ stirred batch filtration equipment, from Sterlitect Corporation, with a magnetic stirrer. The membrane effective filtration area is $1.26 \times 10^{-3} \mathrm{~m}^{2}$. Each tested membrane was fitted in the equipment. The cell was operated at a constant transmembrane pressure (TMP) of 1 bar, regulated with high purity nitrogen gas and stirred at $250 \mathrm{rpm}$. Initially, the membrane sheet was cleaned with distilled water. The distilled water was further utilized to get the measurement the permeate flux. The membrane permeate flux, $\mathrm{J}_{\mathrm{p}}\left(\mathrm{m}^{3} / \mathrm{m}^{2} / \mathrm{h}\right)$ was determined gravimetrically using a weighing scale. The permeate flux was obtained via the measurement of the volume of collected permeate in a given timespan divided by the surface area of membrane, utilizing Eq. (1).

$\mathrm{J}_{\mathrm{p}}=\frac{\mathrm{V}_{\mathrm{p}}}{\mathrm{A} \times \Delta \mathrm{t}}$

where $V_{p}$ is the permeate volume $\left(\mathrm{m}^{3}\right)$ collected during the sampling time $\Delta t(\mathrm{~h})$ and $\mathrm{A}$ is the effective surface area of membrane.

\section{Results and discussion}

The FTIR spectra of the membranes were recorded in the region of $4000-500 \mathrm{~cm}^{-1}$. The FT-IR spectra of the membrane with different amounts of HDPE, chitosan and sisal fiber, are depicted in Fig. 1. FT-IR spectrum of $100 \%$ HDPE does not have pronounced peaks, as it shows that no new functional groups were formed in the membrane, which indicates that the composite membrane was fabricated by a simple melt mixing of HDPE. The IR spectra of the polyethylene/chitosan/sisal fiber membranes of different contents show a broad and prominent peak with wave numbers of between $3000 \mathrm{~cm}^{-1}$ and $2850 \mathrm{~cm}^{-1}$, corresponding to $\mathrm{C}-\mathrm{H}$ stretching of the alkanes group of polyethylene, cellulose in sisal fiber and chitosan. The peaks in this wave numbers range is an indication of a new $\mathrm{O}-\mathrm{H}$ stretching in the ring; further confirming a reaction amid the $\mathrm{NH}_{2}$ groups (chitosan and sisal) and the alkanes groups of HDPE, which was probably due to melt-blending of the composites. The absorption band between wave numbers $1650 \mathrm{~cm}^{-1}$ and $1580 \mathrm{~cm}^{-1}$, are characterized as the $\mathrm{N}-\mathrm{H}$ bending bond from the functional group of $1^{\circ}$ amines of the sisal fiber and chitosan. They are in accordance to the vibrations of the carbonyl bonds ( $\mathrm{CO}$ ) of the amide groups and protonated amine groups (-CONH-), respectively $[13,14]$. In comparison with pure HDPE membrane, the composite membranes show strong absorption peak at $3000 \mathrm{~cm}^{-1}$ and $2850 \mathrm{~cm}^{-1}$, corresponding to a strong $\mathrm{C}-\mathrm{H}$ stretching of the alkanes group of cellulose in sisal fiber and chitosan. Furthermore, the composite exhibit a very broad peak between $3000 \mathrm{~cm}^{-1}$ and $2850 \mathrm{~cm}^{-1}$, indicating the existence of $\mathrm{OH}$ group in the composite. From the FTIR result, it was established that the $\mathrm{NH}_{2}$ groups in the composites formed a chemical bond with the alkane groups.

X-ray diffraction (XRD) patterns of HDPE/chitosan/sisal fiber membranes is shown in Fig. 2. The XRD patterns showed the main

Table 1

Compositions of materials utilized for the fabrication of the composite membranes.

\begin{tabular}{|c|c|c|c|c|}
\hline Samples & $\operatorname{HDPE}(w / w)$ & Chitosan (w/w) & Sisal Fiber $(w / w)$ & Total \\
\hline Membrane 1 & 100 & 0 & 0 & 100 \\
\hline Membrane 2 & 92 & 8 & 0 & 100 \\
\hline Membrane 3 & 92 & 0 & 8 & 100 \\
\hline Membrane 4 & 84 & 8 & 8 & 100 \\
\hline Membrane 5 & 86 & 4 & 10 & 100 \\
\hline Membrane 6 & 86 & 10 & 4 & 100 \\
\hline
\end{tabular}




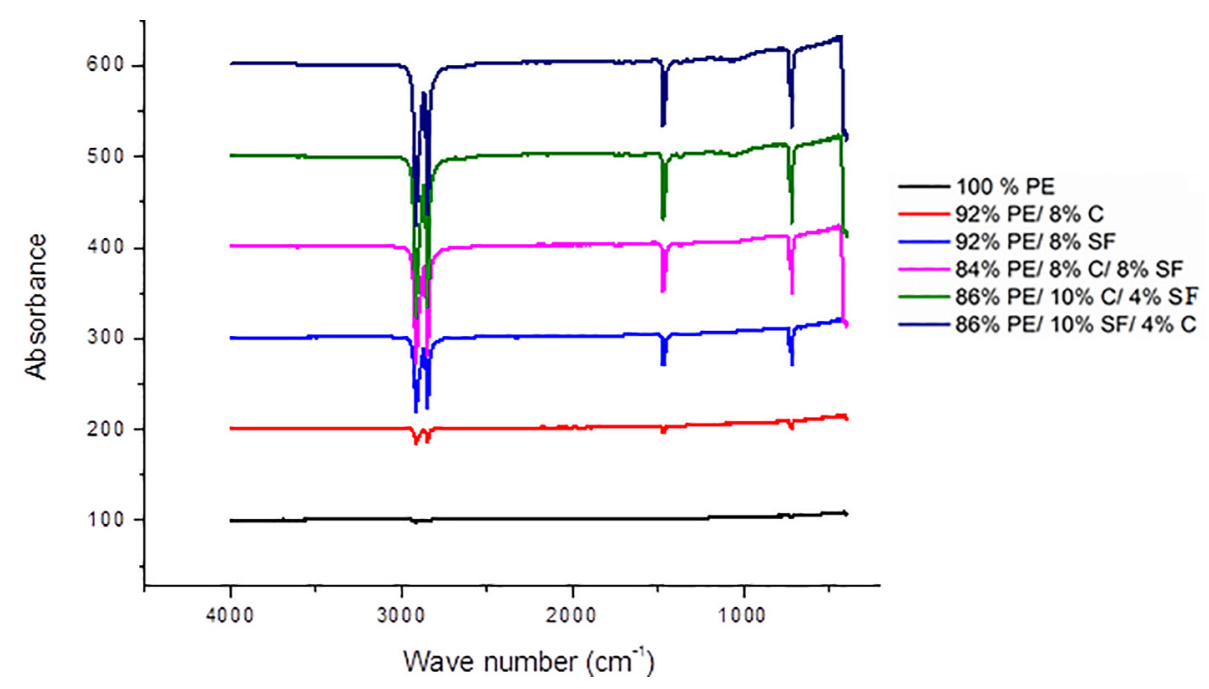

Fig. 1. FTIR spectra of membrane composites.

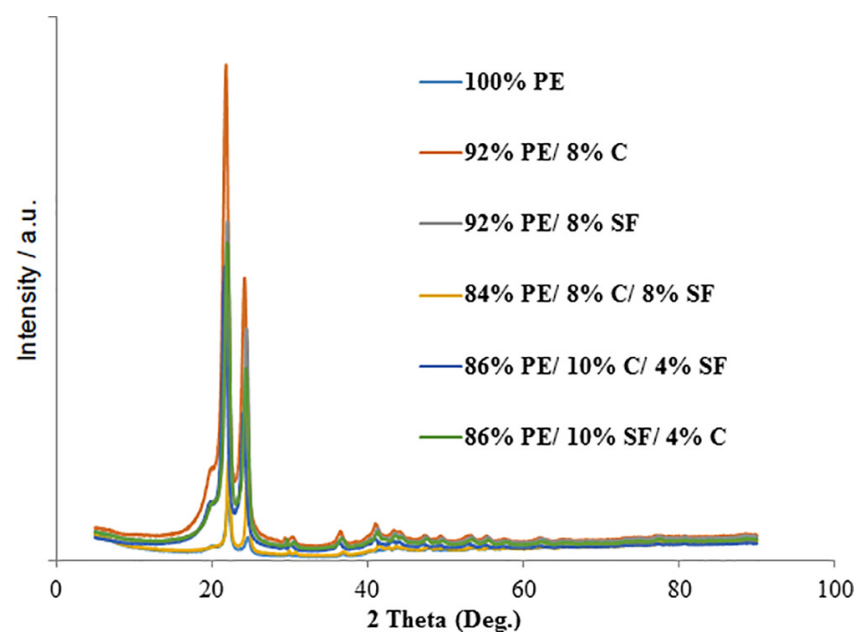

Fig. 2. X-ray diffraction details of HDPE and composite membranes.

sharp diffraction peaks of $\alpha$ phase which is the membranes principal phase and it's around $2 \theta=20^{\circ}$ and $25^{\circ}$. The XRD results suggest that there are good compatibility and interaction between the blend molecules of the membranes. The semi-crystalline nature of polymers is indicated by these sharp peaks [15]. For the blends of $100 \% \mathrm{PE}, 84 \% \mathrm{PE} / 8 \% \mathrm{C} / 8 \% \mathrm{SF}$ and $86 \% \mathrm{PE} / 10 \% \mathrm{C} / 4 \% \mathrm{SF}$, the percentage crystallinity was found to decrease when compared to $92 \% \mathrm{PE} / 8 \% \mathrm{C}$, $92 \% \mathrm{PE} / 8 \% \mathrm{SF}$ and $86 \% \mathrm{PE} / 10 \% \mathrm{SF} / 4 \% \mathrm{C}$ membranes. The later membranes initially showed variations of intensity in the low diffraction angle range; these variations indicate high amorphous nature of the membranes. The amorphous nature is directly related to permeate flux; it is therefore envisaged that the membranes will experience increase in permeate flux [15]. Furthermore, upsurge in the content of chitosan resulted in the disruption of hydrogen bonding in the membrane which led in the reduction of crystallinity in the composite membranes [16]. For 100\% PE, it shows that polyethylene exhibited semicrystalline nature as the molecules pack in the crystallites. Hence, a tough product was formed as a result of the sturdy intermolecular forces allied with close chain packing in the crystallites. In this context, it was obvious that the amorphous domain in the $100 \%$ PE polymer membrane was significantly augmented (having a deceased in the degree of crystallinity) when compared to $84 \% \mathrm{PE} / 8 \% \mathrm{C} / 8 \% \mathrm{SF}$. Thus, the peak intensity ratio of pure HDPE membrane was low. The XRD diffractogram of the membrane composites indicates a relatively high crystalline nature of the membranes, when compared to the HDPE membrane.

Fig. 3a reveals the membranes dense nature with pores. Fig. 3b, $3 \mathrm{~d}$ and $3 \mathrm{e}$ show large visible pores and exhibit large interspace between the pores. This result might be explained by the fact that: high quantity of chitosan in the blends increased the porosity of the membranes synthesized; this could be as a result of the protonation of the $\mathrm{NH}_{2}$ - groups on the chitosan and sisal fiber backbone, as observed in Fig. 1. Fig. 3c and 3f show the inter-twined fibrous network with some visible pores of the respective membranes and they appear to have rough surfaces when compared to other membranes composites. The inter-twined fibrous network is more pronounced with increasing amount of sisal fiber. The presence of submicron particles in Fig. $3 \mathrm{c}$ and $3 \mathrm{f}$ could have been the result of the addition of chitosan powder to the membranes. SEM images (cross-section) of composites membranes of different ratios are presented in Fig. 4. The skin stratum structures seen were really different, depending on the blend composition. The skin layer structure was rough and has more scaffold formation with larger voids for the blends of $92 \% \mathrm{PE} / 8 \% \mathrm{C}, 92 \% \mathrm{PE} / 8 \% \mathrm{SR}$ and $84 \% \mathrm{PE} / 8 \%$ $\mathrm{C} / 8 \% \mathrm{SF}$ (Fig. 4b-4d). The membrane with high percent of sisal fiber showed a rougher surface. In addition, the dense nature of the membranes comprises of a fibrous scaffold as the porous surface, and an active layer. The fibrous scaffold is envisage to enhance the performance of the membranes. Furthermore, cryogenically fracturing process was done to study the general behavior of failure and fouling characteristics. It offered some facts regarding the micro- and nano-scale internal structures of the composite, together with the spatial relationship of foulants with respect to the composite membranes. The fractured cross-sections of the membrane composites shows common feature of a porous microstructure.

It is a common knowledge that the penetrability of liquid through porous material is attained via surface roughness, sizes of pores and porosity. Fig. 5 presents the relationship between filtration time and permeate flux of the blended membranes, which shows the porous nature of the membranes. Yoon et al. [17] stated that the measurement of permeate flux represents an imperative preliminary stage of filtration study prior to further filtration study. The flux of $100 \%$ PE membrane through the membrane was very low due to the dense nature of the membrane (observed in Fig. 5a). The flux of: 92\% PE/8\%C membrane, 92\% PE/8\%SF mem- 

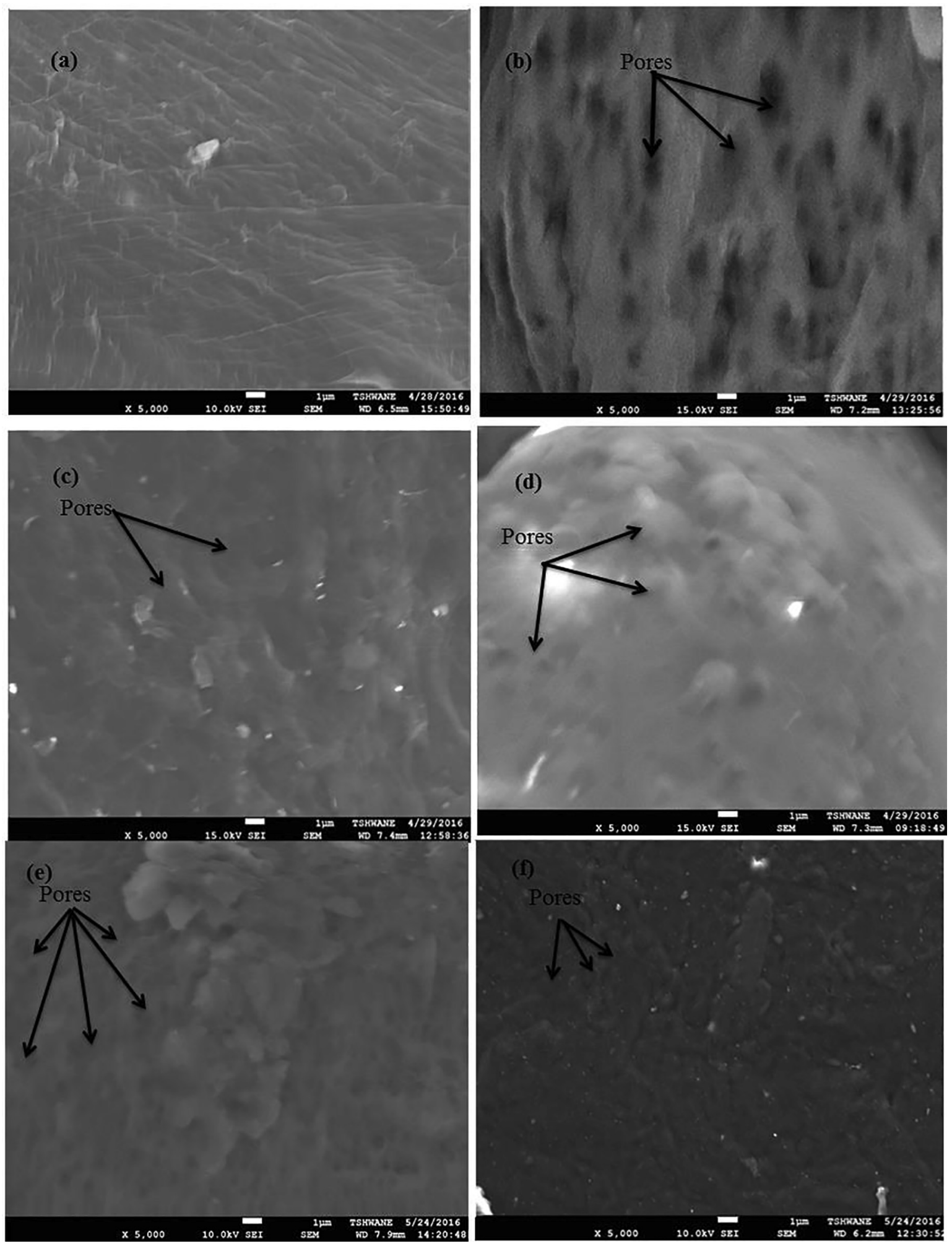

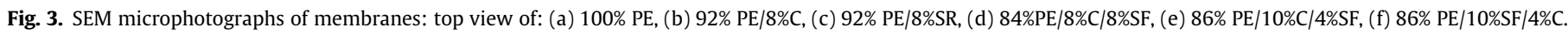

brane and $84 \% \mathrm{PE} / 8 \% \mathrm{C} / 8 \% \mathrm{SF}$ membrane are larger than flux of $100 \%$ PE membrane. This could be as a result of the protonation of the $\mathrm{NH}_{2}$ - groups on the chitosan and sisal fiber backbones, as observed in Fig. 1. However, pure water permeabilities of $92 \% \mathrm{PE} / 8 \% \mathrm{SF}$ and $86 \% \mathrm{PE} / 4 \% \mathrm{C} / 10 \mathrm{SF}$ membranes are considerably larger than the other four formulations under the same pressure. This was due to the inter-twined fibrous network and the rough surface that was more pronounced with increasing amount of sisal fiber (see Fig. $3 \mathrm{c}$ and $3 \mathrm{f}$ ). Some researchers discovered that higher roughness is responsible for increased water flux $[18,19]$. Therefore, the highest flux of the membrane is accredited to its roughness, wider pore size and excellent porosity, while the low water flux of the other blended membranes is accredited to relatively less rough surface and poor porosity. 
(a)
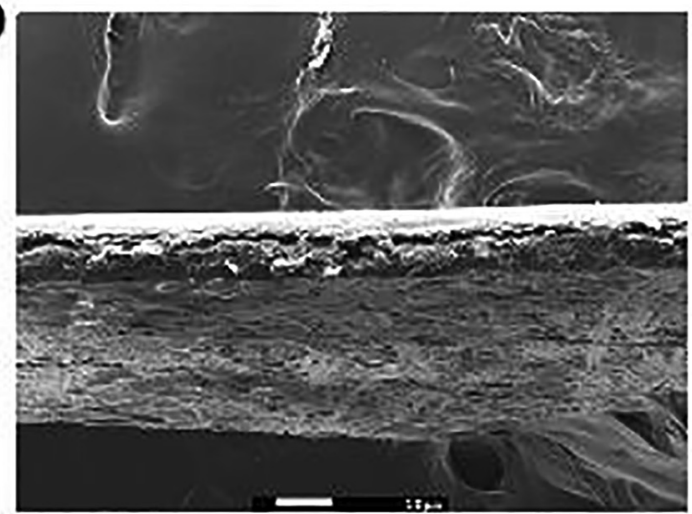

\section{(c)}

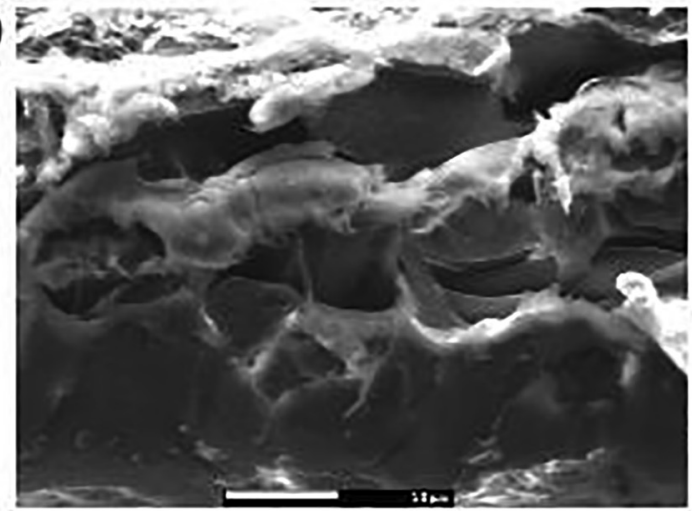

(e)

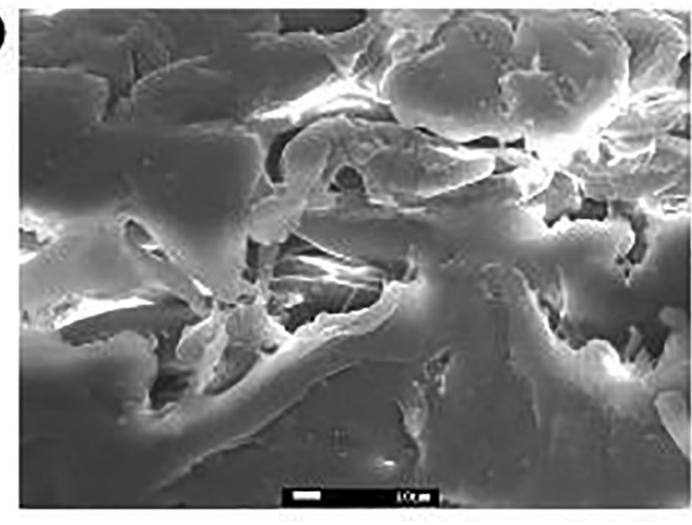

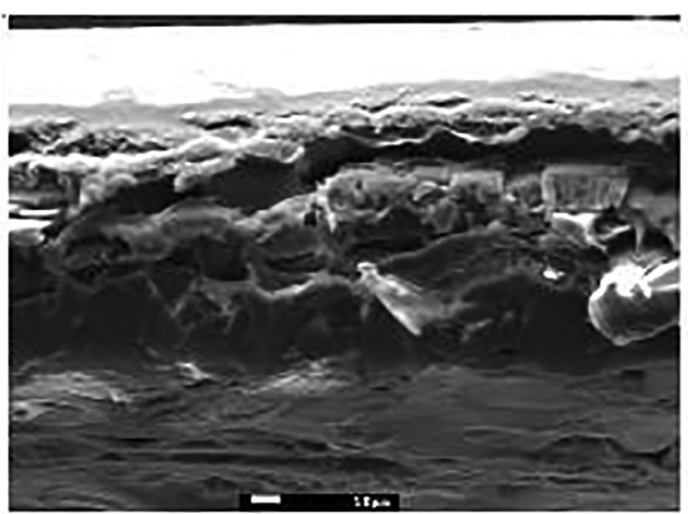

(b)

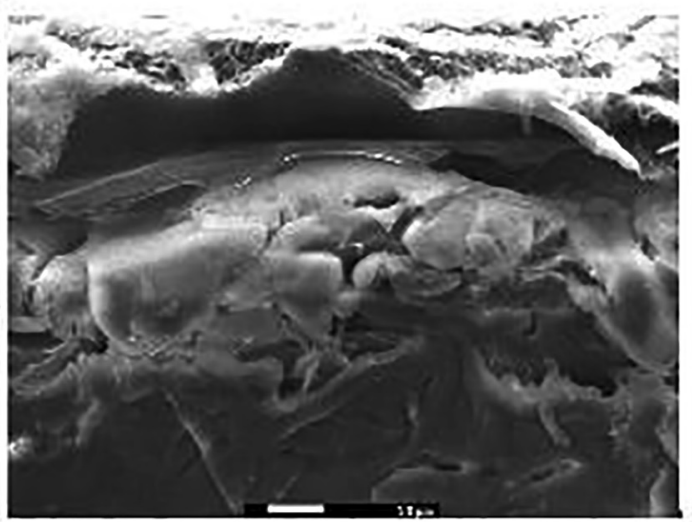

(d)

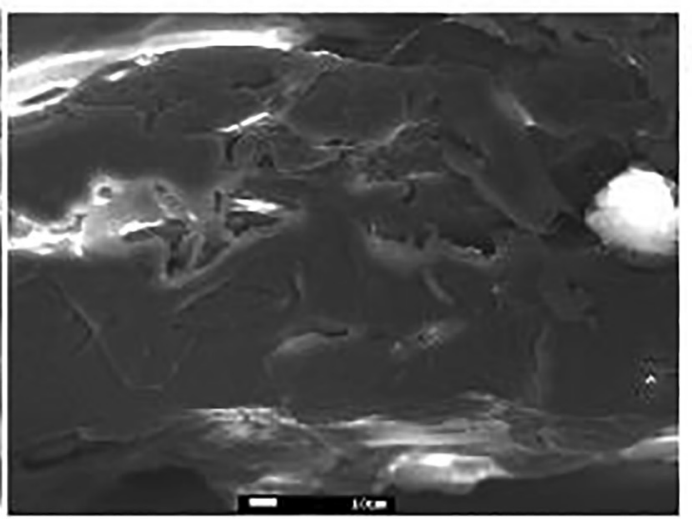

\section{(f)}

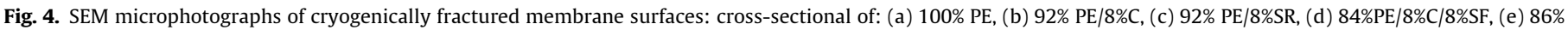
$\mathrm{PE} / 10 \% \mathrm{C} / 4 \% \mathrm{SF}$, (f) $86 \% \mathrm{PE} / 10 \% \mathrm{SF} / 4 \% \mathrm{C}$.

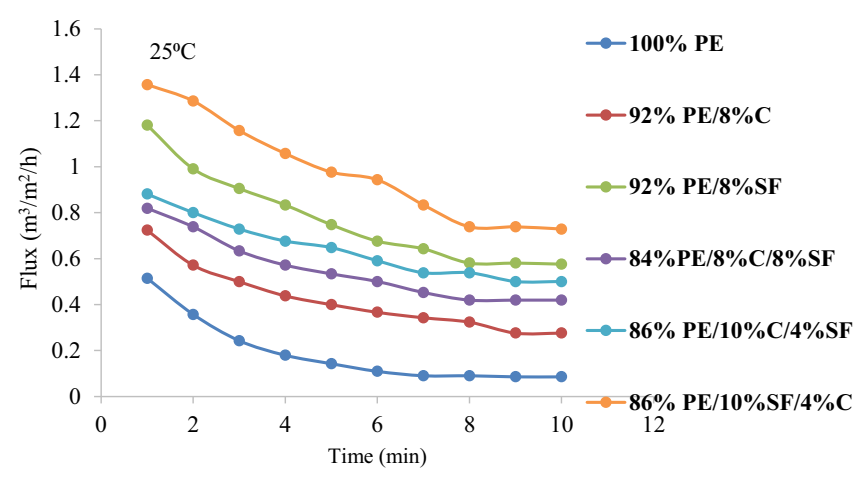

Fig. 5. Flux of distilled water as a function of time for pure water permeability test.

\section{Applications of evaluation of Chitosan/Sisal fiber/ Polyethylene membranes}

Chitosan is an adaptable bio polymer that possess exceptional structural topographies. Chitosan effectively binds with fine suspended particles, bacteria, heavy metals, pollutants etc. The nature of chitosan (biocompatible and biodegradable) makes it a prospective material for purification of water [20]. Hence, Globally, water treatment plants utilizes chitosan for the removal of heavy metals, oils, grease, macro pollutant and the fine particulate matter that has resulted in turbidity in wastewater streams [21]. Sisal fibers has a unique properties of enhancing fiber-polymer matrix compatibility to ensure a substantial upsurge in tensile strength. Hence, the incorporation of chitosan and sisal fiber in HDPE provides the composite it utilization in desalination and water treatment for the removal of heavy metals, grease, oil, dye, macro pollutant from wastewater. 


\section{Conclusion}

In order to acquire a deep understanding of the mechanism that exits among the constituents of chitosan/HDPE/SF membrane composites, it was necessary for the composites to be structurally and physically characterized. A thorough knowledge of the microstructure of these composites was essential for an understanding of the structure-property-activity relationships. The interaction of the reaction mechanisms in chitosan/HDPE/SF membranes has been investigated. It is suggested that the blended composites have a semi-crystalline nature. The SEM images revealed the incorporation of chitosan and sisal fiber within the asymmetric composite membranes. The addition of chitosan and sisal fiber to HDPE favours the pure water permeability; however, the integration of sisal fibers into the HDPE matrix, appreciably upsurge the water flux. The properties of the membrane composite can be systematically ordered via the alteration of the weights \% of chitosan and sisal fiber in the composites.

\section{CRediT authorship contribution statement}

O. Agboola: Conceptualization, Investigation. O.S.I. Fayomi: Methodology, Investigation. E.R. Sadiku: Supervision. A. Ayoola: Supervision. T. Mokrani: Investigation. B.S. Mbuli: . P. Popoola: Supervision. G. Perry: .

\section{Declaration of Competing Interest}

The authors declare that they have no known competing financial interests or personal relationships that could have appeared to influence the work reported in this paper.

\section{Acknowledgement}

The authors acknowledges Covenant University for the financial support provided for the publication of this manuscript.

\section{References}

[1] A. Kofi, D. Kofi, L. Toubal, Int. J. Eng. Res. Dev. 10 (2016) 29.

[2] K. Abron, M.U.B. Wahit, S. Bahraejan, Sci. Res. Essays 6 (2011) 5895.

[3] O. Sadiku-Agboola, E.R. Sadiku, Theoretical modeling of nanostructured formation in polymer blends, Chapter 3 in the book entitled 'Nanostructured polymer blends'. (2014) Elsevier, USA.

[4] S.M. Lomakin, L. Novokshonova, P.N. Brevnov, A.N. Shchegolikhin, J. Mater. Sci. 43 (2007) 1340.

[5] O. Agboola, E.R. Sadiku, T. Mokrani, Nanomembrane materials based on polymer blends, Chapter 6 in the book entitled "Design and Applications of Nanostructured Polymer Blends and Nanocomposite Systems, (2016) Elsevier, USA.

[6] P.M. Khanam, M.A.A. AlMaadee, Adv. Manufact. Polym. Compos. Sci. 1 (2015) 63.

[7] F.A. Silva, N. Chawla, R.D.T. Filho, Compos. Sci. Technol. 68 (2008) 3438.

[8] M. Zeng, Z. Fang, C. Xu, J. Appl. Polym. Sci. 91 (2004) 2840.

[9] A. Niekraszewicz, Chitosan medical dressing, Fibers Text. East. Eur. 13 (2005) 16.

[10] S. Bandehali, A. Moghadassi, F. Parvizian, Y. Zhang, S.M. Hosseinia, J. Shen, Sep. Purif. Technol. 242 (2020).

[11] A. Giwa, S.W. Hasan, Sep. Purif. Technol. 241 (2020).

[12] S. Saqib, S. Rafiq, N. Muhammad, A.L. Khan, A. Mukhtar, N.B. Mellon, Z. Man, S. Ullah, A.G. Al-Sehemi, F. Jamil, Chem. Eng. Sci. 218 (2020).

[13] J. Kumirska, M. Czerwicka, Z. Kaczynski, A. Bychowska, K. Brzozowski, J Thöming, P. Stepnowski, Marine Drugs. 8 (2010) 1567.

[14] Z. Zakaria, Z. Izzah, M. Jawaid, A. Hassan, BioResources 7 (2012) 5568.

[15] P.N. Sudha, P. Angelin Vinodhini, K. Sangeetha, L. Srinivasan, T. Gomathi, V. Jayachandran, K. Se Kwon,, Der Pharmacia Lett. 6 (2014) 37.

[16] S. Janakiram, M. Ahmadi, Z. Dai, L. Ansaloni, L. Deng, Membranes 8 (2018) 1.

[17] Y. Yoon, G. Amy, J. Cho, J. Pellegrino, Sep. Purif. Technol. 39 (2004) 2105.

[18] M. Hirose, H. Itoh, Y. Minamizaki, Proceedings of the international congress on membranes and membrane process held in Japan (1996) 18- 23 August, 1996.

[19] Y.X. Gao, Y.H. Chen, Membr. Sci. Technol. 18 (1998) 11.

[20] H. Chopra, G. Ruhi, Pharm. Innov. J. 5 (2016) 92.

[21] W.J. Hennen, Chitosan Natural Fat Blocker (1996) Woodlan Publishing, New York. 